\title{
An approach to optimizing the train timetable on a railway network
}

\author{
M. Jacyna \& P. Gołębiowski \\ Faculty of Transport, Warsaw University of Technology, Poland
}

\begin{abstract}
The paper presents an approach to optimizing the train timetable on a railway network using a multilevel optimization method. The development of a rational timetable has been carried out in two stages: (1) the computation of transport offer and (2) the physical construction of a timetable. Maximizing the number of passengers transported in direct relations, minimizing operating costs and minimizing the number of rolling stock required to operate the system is adopted at the first stage as an evaluation subcriteria. In a second step, maximizing profits from the introduction of the train on the route at a specific time is adopted. This approach is the basis and the next step will be implemented in the form of an optimization procedure using a hybrid algorithm: the $A^{*}$ search algorithm and Bees Algorithm.

Keywords: multilevel optimization, computation of rail transport offer, train timetabling, $A^{*}$ search algorithm, Bees Algorithm.
\end{abstract}

\section{Introduction}

The movement of trains on the railway network, due to the need to provide the highest degree of safety, must be appropriately structured. This requires the determination of:

- the sequence of trains on particular sections of railway lines,

- the train journey times on individual parts of the railway lines and the spacing of times regarding both the open line and the station,

- places for overtaking, crossings of trains and stopping,

- types of train sets and their parameters to handle the assumed demand for transport, 
- division of tasks between the railway undertakings, including the division of tasks between the various market segments of transportation needs.

It follows from the foregoing that the organization of railway traffic is a complex decision problem. Complexity is the result of many factors that should be taken into account. For this reason, among the research areas relating to the organization of railway traffic, the construction of a train timetable takes significant place.

A train timetable [2] is a basic element for the organization of transport services representing a railway operations plan, according to which the movement of all trains on the railway network or its parts takes place. A train timetable is prepared based on a graphic timetable, which is a graphical representation of the coordinate time $t$ and way $s$ trains on a particular section of the railroad.

The development of a rational timetable was carried out in two stages:

1. computation of a rail transport offer where at first shall be determined the optimal courses of communication lines, and for each line shall be allocated the type of train set for the operation and frequency,

2. construction of a graphic timetable, where all possible paths on a graphic timetable shall be designated and carried on a real train path chart.

Many models for the computation of a rail transport offer are described in the literature (Line Planning Problem - LPP) and the construction of graphic timetables (Train Timetabling/Scheduling Problem - TTP/TSP). The essence of the first problem is to search for the optimal courses of communication lines, for which is assigned the type of train set for handling. The second problem is the routing of trains on the graphic timetable. Classical mathematical models for both problems are described by Caprara et al. in [6]. Other researchers have applied, as optimization criterion, the process of rail transport offer computation, among others; the maximization of the number of carried passengers used for solving the branch-and-bound method [9] and integer linear programming [4]. As an indicator of the solution assessment quality the minimization of the operating costs was solved using integer linear programming [7] and the branch-and-cut method [12]. To compute a rail transport offer, which assumed a cyclical timetable the PESP (Periodic Event Scheduling Problem) method was used [23]. The objective function was used to determine the minimization of interchanges between train sets for passengers [24]. Lagrangian relaxation and heuristic methods were used to solve this formulation. During the computation of the rail transport offer it should be remembered that the distribution of traffic flow on the railway network has been carried out taking into account the principles of the design of a proecological transport system [13].

The process of construction graphic timetable has been divided into two groups of problems, the non-cyclic and cyclic construction of train timetables. In terms of the non-cyclic timetable many literature references show formalisms of Multi Integer Linear Programming. Decision variables describe the moments of departure and arrival of trains to particular operating offices, along with determining the sequence in which trains move. In some models the order of train departures from the first station is presented in the form of separable restrictions [25]. The solution of this problem was found by the branch-and-bound method. 
Another developed model has the primary objective of realizing the execution of the plan and not optimizing the objective function [13]. The mathematical model described in [3] discretized time into one-minute slots, and the solution was achieved by using the integer linear programming method. For the construction of the train timetable a model of machines scheduling was used (Job-Shop Scheduling Model) [18]. The formulation for the problem of graphic timetables was constructed using the tools of graph theory presented in [5].

The construction of a cyclic train timetable is based on the model of PESP, as shown in $[17,23]$. As an indicator of the solution quality assessment used among others minimization of waiting times by passengers and used to solve genetic algorithms [19]. For the PESP model also introduced the stochastic elements [16].

All cited works concerned with the second phase of graphic timetable construction refer to a limited fragment of the railway network on which the experiments are conducted. There is no information on the use of the presented models to a larger scale of the problem, such as the area of the country, or even the district.

Research in a similar frame to that described in this paper was conducted by Albrecht [1]. He used a multilevel optimization method to construct train timetables for suburban railways. For the process of rail transport computation he used the classical mathematical model described by Caprara et al. [6]. As the criterion for optimality he used the cost approach and the solution was found from the branch-and-bound method. However, for the second phase of graphic timetable construction he chose only to designate the proposed departure hours from the initial station used for solving the genetic algorithm.

\section{Factors affecting on the process of designing the timetable}

The process of train timetable designing affect many factors. At the first stage of train timetable construction, (the computation of transport offer), there are three groups of factors. The first group includes factors shaping the volume of need for transportation. It includes [15]:

- population of the concerned area,

- spatial arrangement of the settlement network,

- the location places of, work, study, shopping malls, service companies and administrative centres,

- the location of spas and areas which are attractive for tourists,

- the system of economic governance,

- intensity of cooperation in economy, science and technology, culture, etc., with other regions of the country and foreign countries,

- the level of affluence of the society and the balance of free time,

- attractiveness of the rail transport available (the level of quality of transport services and their prices).

The second group are the economic factors. The volume of rail transport on offer depends, inter alia, on grants awarded by the transport organizer in passenger transport, or on the size of the transport order by the client transmitting/receiving 
freight. It is in the interest of the carrier that its activities should not generate losses, and instead only generate profits.

The third group are the technical factors. The shape of rail transport offer will depend on:

- the number of rolling stock, which is managed by the carrier,

- the capacity of rolling stock,

- the length of train journey time,

- type of traction,

- etc.

The second stage of the train timetable construction process, (the construction of the timetable), is affected by many technical and exploitation factors. They can be divided into three subgroups:

- factors dependent on the infrastructure and the infrastructure manage, this subgroup should include all factors generated by the infrastructure elements (their state, technical and exploitation characteristics, etc.) and factors forced by the infrastructure manager (rules, regulations, etc.),

- factors dependent on the superstructure, this subgroup should include all the factors originating from the rolling stock and forced by regulations relating to the rolling stock,

- factors dependent on the railway undertaking, this subgroup should include all factors related to the wishes and demands on the railway undertakings.

\section{The mathematical model of train timetable constructing (MKWRP)}

\subsection{The assumptions}

Until now the organization of railway traffic problems were dealt with separately. The area for which the traffic organization was prepared was clearly defined (e.g. for single-track lines, where the number of tracks on the stations are infinite). Researchers also tried simultaneous optimization of communication lines and construction of train timetables on the one stage. However, as already mentioned in the first point, the second stage was limited to determining the departure hours from the beginning stations. New tools should be looked for that will facilitate the work of the organizers of railway traffic.

For the construction of train timetables on several aspects are mentioned in point one, one of the possible methods to use is multilevel optimization. This method consists of sequential decision making in a specific order [10]. Subsequent decisions must provide an optimal strategy relative to the state which is the result of the first decision, regardless of the initial state. Presented in this article is an approach which assumes a solution using multi-level optimization methods. Point four presents the algorithm of method.

The KWRP (Graphic Train Timetable Constructing) model consists of two models. The first, the model MKOP (Model of Designing Rail Transport Offer), concerns the problem of computation rail transport offer. Its essence is the allocation of the type of train composition, their frequencies on the designated 
communication lines and calculation of the traffic flow volume operated by routes of trains in direct relations. The second model, the model MKWR, (Physical Construction Train Timetable), refers to the physical graphic train timetable construction. A description of the two models is presented in sections 3.2 and 3.3.

As indicators to assess the quality of solutions in the model MKOP use the following functions:

- $f_{1}(\mathbf{D})-$ maximization of the number of passengers transported in direct relations, written in the form of expression:

$$
f_{1}(\mathbf{D})=\sum_{\text {okrdob } \in \text { OKRDOB B }} \sum_{\boldsymbol{B}_{\text {kat }} \in \boldsymbol{T}_{\text {kat }}} \sum_{p_{k \text { kat }}^{\text {okddob }}\left(w k, w k^{\prime}\right) \in \mathbf{P}_{\text {kat }}^{\text {oktdob }}} d\left(t_{\text {kat }}, p_{k a t}^{\text {okrdob }}\left(w k, w k^{\prime}\right), o k r d o b\right) \longrightarrow \max
$$

- $f_{2}(\mathbf{X})$ - minimization of operating costs, written in the form of expression:

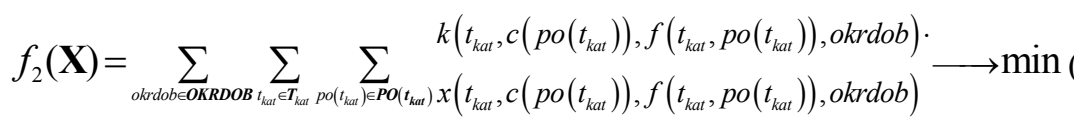

where: $k\left(t_{k a t}, c\left(p o\left(t_{k a t}\right)\right), f\left(t_{k a t}, p o\left(t_{k a t}\right)\right), o k r d o b\right)$ are the operational costs associated with the launch of the train on the route number $t_{k a t}$, which is supported by train composition of type $c\left(p o\left(t_{k a t}\right)\right)$ with the frequency $f\left(t_{k a t}, p o\left(t_{k a t}\right)\right)$ for a specified period of the day,

- $f_{3}(\mathbf{X})$ - minimization the number of different types of trains required to operate written in the form of expression:

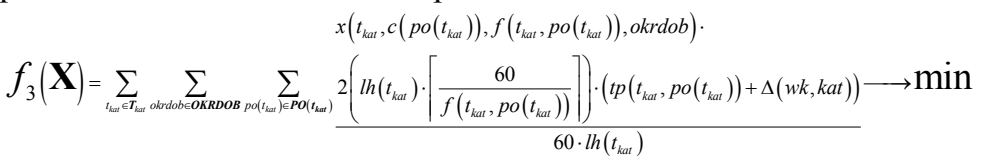

An indicator of the quality assessment solutions used in the model MKWR function, which describes the maximization of profits related to the launch of the train on the graphic timetable on the arc, are written in the form of the expression:

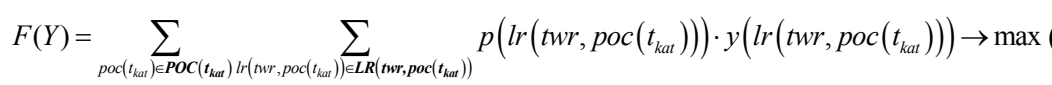

where: $p\left(\operatorname{lr}\left(t w r, p o c\left(t_{k a t}\right)\right)\right)$ is the profit associated with the launch of a train along the arc $\operatorname{lr}\left(t w r, p o c\left(t_{k a t}\right)\right)$ (the difference between the reference journey time of a train on the arc and real-journey time on the arc) written in the form of the expression:

$$
p\left(\operatorname{lr}\left(t w r, \operatorname{poc}\left(t_{k a t}\right)\right)\right)=t_{w}\left(\operatorname{lr}\left(t w r, \operatorname{poc}\left(t_{k a t}\right)\right)\right)-t_{r z}\left(\operatorname{lr}\left(t w r, \operatorname{poc}\left(t_{k a t}\right)\right)\right)
$$

\subsection{Model of designing rail transport offer (MKOP)}

In the designing of transport offer in rail transport the problem is searching for optimal courses of communication lines and allocating them to the types of the 
train sets and frequency. The objective is to maximize the volume of traffic flow transported in direct relations, minimize operating costs and minimize the number of train types which are necessary to handle the system. With the defined optimization problem the formulation of the task of computing rail transport offer will have the following form.

For the data:
$\boldsymbol{G K}=\langle\boldsymbol{W K}, \boldsymbol{L K}\rangle$
graph showing the railway network,
WK
$L K$
OKRDOB
$\boldsymbol{K A T}$
$\mathbf{P}_{k a t}^{\text {okrdob }}$
$p_{k a t}^{o k r d o b}\left(w k, w k^{\prime}\right)$
$T_{\text {kat }}$
$\boldsymbol{L K}_{\boldsymbol{t}_{\text {kat }}}$
$\boldsymbol{P O}\left(\boldsymbol{t}_{\text {kat }}\right)$
$c\left(p o\left(t_{\text {kat }}\right)\right)$
$l\left(\right.$ po $\left.\left(t_{\text {kat }}\right)\right)$
$f\left(t_{\text {kat }}, p o\left(t_{\text {kat }}\right)\right)$
$\operatorname{lh}\left(t_{\text {kat }}\right)$
$\operatorname{tp}\left(t_{k a t}, p o\left(t_{k a t}\right)\right)$
$\Delta(w k, k a t)$
set of numbers of operating control points and forwarding offices $w k, w k \in \boldsymbol{W K}$,
set of connections between operating control points and forwarding offices $l k, l k \in \boldsymbol{L K}$,
set of numbers of periods of day okrdob, okrdob $\in$ OKRDOB,
set of numbers of segments of the demand for transport services kat, kat $\in \boldsymbol{K A T}$ (categories of trains),
OD matrices (matrices of traffic flows between sources and destinations) developed for various periods of the day $o k r d o b$ and various segments of the demand kat, traffic flow in relation ( $\left.w k, w k^{\prime}\right)$ to different periods of the day okrdob and individual segments of demand kat, set of the number of routes (communication lines) $t_{\text {kat }}$, $t_{\text {kat }} \in \boldsymbol{T}_{\text {kat, }}$ are particular categories kat,
set of edges representing routes with number $t_{k a t}$ set of number of trains types $p o\left(t_{k a t}\right), p o\left(t_{k a t}\right) \in \boldsymbol{P O}\left(\boldsymbol{t}_{k a t}\right)$, parameter specifying the capacity of the train set type $p o\left(t_{k a t}\right)$, parameter specifying the number of train sets of a particular type $p o\left(t_{k a t}\right)$,
parameter specifying frequency of train set types $p o\left(t_{k a t}\right)$ on route $t_{\text {kat }}$,
parameter specifying the number of running hours on route $t_{\text {kat }}$,
parameter specifying journey time of train set type $p o\left(t_{k a t}\right)$ along the route $t_{k a t}$,
parameter specifying the average stop time at a node $w k$ train of category kat.

Shall be determined such that an assignment to routes $t_{k a t}$, the type of train set $c\left(p o\left(t_{k a t}\right)\right)$ and frequency $f\left(t_{k a t} p o\left(t_{k a t}\right)\right)$ for a specific part of the day okrdob, so designate elements of the matrix $\mathbf{X}$ :

$$
\mathbf{X}=\left[x\left(t_{\text {kat }}, c\left(p o\left(t_{\text {kat }}\right)\right), f\left(t_{\text {kat }}, p o\left(t_{\text {kat }}\right)\right), o k r d o b\right)\right]
$$


Designate the volume of traffic flow in direct relations on route $t_{k a t}$, between nodes numbered $w k$ and $w k^{\prime}$ in trains category kat, in a particular section of the day $o k r d o b$, to be written in form of matrix $\mathbf{D}$ :

$$
\mathbf{D}=\left[d\left(t_{k a t}, p_{k a t}^{o k r d o b}\left(w k, w k^{\prime}\right), o k r d o b\right)\right]
$$

so that the global criterion function:

$$
F(\mathbf{X}, \mathbf{D})=\left[f_{1}(\mathbf{D}), f_{2}(\mathbf{X}), f_{3}(\mathbf{X})\right]
$$

reached extreme value under the following constraints:

- resulting from the technical conditions:

1) each route $t_{k a t}$ category kat in each period of day okrdob should be supported by a train set, with a capacity $c\left(p o\left(t_{k a t}\right)\right)$, with frequency $f\left(t_{\text {kat }}, p o\left(t_{\text {kat }}\right)\right)$,

2) the number of train sets of a particular type $p o\left(t_{k a t}\right)$ assigned to handle all potential communication lines $t_{\text {kat }}$, the particular categories of kat during all periods of day okrdob, should be less than or equal to the number of train sets of particular type owned by the railway undertaking $l\left(p o\left(t_{k a t}\right)\right)$,

- resulting from the transport of traffic flow:

1) supply of places on the route $t_{k a t}$ during the period of day okrdob should be greater than or equal to the demand for transport on a particular route $p_{k a t}{ }^{o k d o b}(w k, w k)$,

2) the volume of traffic flow which is to be transported in direct relations on the given line $t_{k a t}$ should be less than or equal to the supply of seats on route $t_{k a t}$

3) the volume of traffic flow which is to be transported in direct relations on route $t_{k a t}$, the particular category kat, should be less than or equal to traffic flow to transport from node $w k$ to node $w k^{\prime}$,

4) values of decision variables with the interpretation of volume of traffic flow, which is to be transported in direct relation on the route $t_{k a t}$, should not take negative values.

\subsection{Model of physical construction train timetable (MKWR)}

The issue of the physical construction train timetable is the problem in searching for the actual train paths on the graphic timetable which will lead to the maximization of profits which result from the passage of a train on the route. Formulation of the optimization task for the physical construction train timetable will have the following form:

For the data:

$W K, L K, P O\left(t_{k a t}\right), T_{k a t}$, $f\left(t_{k a t}, p o\left(t_{k a t}\right)\right), \operatorname{lh}\left(t_{k a t}\right), l\left(p o\left(t_{k a t}\right)\right)$ as the model MKOP,

$\operatorname{POC}\left(\boldsymbol{t}_{\text {kat }}\right)$ set of train numbers poc $\left(t_{k a t}\right)$, $\operatorname{poc}\left(t_{k a t}\right) \in \boldsymbol{P O C}\left(\boldsymbol{t}_{k a t}\right)$, to launch on the route $t_{k a t}$, 
$g w\left(\operatorname{poc}\left(t_{\text {kat }}\right)\right)$

\section{TWR}

$G R(t w r)=\langle W R(t w r), L R(t w r)\rangle$

$W R(t w r)$ parameter specifying the leading hour for the train $\operatorname{poc}\left(t_{k a t}\right)$, set of routes numbers $t w r$, $t w r \in \boldsymbol{T} \boldsymbol{W} \boldsymbol{R}$, for which the graphic timetable was created, graph used for the construction train timetables,

set of node numbers, $w r(t w r)$, $w r(t w r) \in \boldsymbol{W R}(\boldsymbol{t w r})$, denoting hours of arrival and departure on graphic timetable $t w r$,

$W R(t w r)=W R P(w k, t w r, p o c(t)) \cup W R O(w k, t w r, p o c(t))$

$\operatorname{WRP}\left(w k, t w r, p o c\left(t_{k a t}\right)\right)$

$W R O\left(w k, t w r, p o c\left(t_{k a t}\right)\right)$

$\operatorname{LR}\left(\boldsymbol{t w r}, \operatorname{poc}\left(\boldsymbol{t}_{\text {kat }}\right)\right)$

WRA $(t w r)$

$W R B(t w r)$

$\operatorname{lrj}\left(l k, p o c\left(t_{k a t}\right)\right)$

$\operatorname{lrp}\left(w k, \operatorname{poc}\left(t_{k a t}\right)\right)$

$\operatorname{lrns}(w k)$

$\operatorname{lrnsz}\left(l k, \operatorname{poc}\left(t_{k a t}\right)\right)$

$\operatorname{lrsk}(w k)$

$t_{r z}\left(\operatorname{lr}\left(t w r, \operatorname{poc}\left(t_{k a t}\right)\right)\right)$

$t_{w}\left(\operatorname{lr}\left(t w r, \operatorname{poc}\left(t_{k a t}\right)\right)\right)$ set of vertices denoting arrivals of trains poc $\left(t_{k a t}\right)$ to the vertices $w k$ on graphic timetable twr,

set of vertices denoting departures of trains $\operatorname{poc}\left(t_{k a t}\right)$ from the vertices $w k$ on graphic timetable $t w r$,

set of edges denoting change of train state $\operatorname{poc}\left(t_{k a t}\right)$ on graphic timetable $t w r$,

set of departure moments from the first node on graphic timetable $t w r$,

set of arrival moments to the last node on graphic timetable $t w r$,

parameter specifying the length of journey time of the train $\operatorname{poc}\left(t_{k a t}\right)$ on the edge $l k$,

parameter specifying the length of the train $\operatorname{poc}\left(t_{k a t}\right)$ stop in the vertex $w k$,

parameter specifying the length of the station time spacing in the vertex $w k$,

parameter specifying the length of the open line time spacing for the train $p o c\left(t_{k a t}\right)$ on the edge $l k$,

parameter specifying the length of the waiting time in the vertex $w k$,

actual duration of the train $\operatorname{poc}\left(t_{k a t}\right)$ state represented by edge $\operatorname{lr}\left(t w r, p o c\left(t_{k a t}\right)\right)$ on graphic timetable $t w r$,

reference duration of the train $\operatorname{poc}\left(t_{k a t}\right)$ state represented by edge $\operatorname{lr}\left(t w r\right.$,poc $\left.\left(t_{\text {kat }}\right)\right)$ on graphic timetable $t w r$.

Determine the values of the decision variables, with the interpretation whether the edge $\operatorname{lr}\left(t w r, p o c\left(t_{k a t}\right)\right)$ placed on graphic timetable for the route $t w r$ relating to the train $\operatorname{poc}\left(t_{k a t}\right)$ is suitable, in the form of a matrix $\mathbf{Y}$ :

$$
\mathbf{Y}=\left[y\left(\operatorname{lr}\left(t w r, \operatorname{poc}\left(t_{k a t}\right)\right)\right)\right]
$$


that the criterion function:

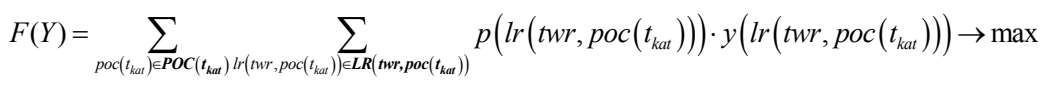

reached a maximize value under the following constraints:

- resulting from the technical conditions:

1) initial vertex on graphic timetable $t w r-w r a(t w r)$ for the train poc $\left(t_{k a t}\right)$ can only have one next vertex,

2) for the intermediate vertex on graphic timetable $t w r-w r(t w r)$, for the train $\operatorname{poc}\left(t_{k a t}\right)$, the number of previous nodes must be equal to the number of the following nodes,

3) final vertex on graphic timetable $t w r-w r b(t w r)$ for the train $p o c\left(t_{k a t}\right)$ can only have one previous vertex,

- resulting from the behavior of safety:

1) for each vertex $w k$, the difference between the arrival moment of the next train poc' $\left(t_{k a t}\right)$ and the departure moment of train poc $\left(t_{k a t}\right)$ must be greater than or equal to the length of the station time spacing,

2) for each vertex $w k$ the departure moment of next train $p o c$ ' $\left(t_{k a t}\right)$ must be greater than or equal to the departure moment of the train $p o c\left(t_{k a t}\right)$ plus the length of open line time spacing,

3) for each vertex $w k$, which are places where trains can terminate and begin running, the difference between the departure moment of the next train $\operatorname{poc}^{\prime}\left(t_{k a t}\right)-w r a\left(t w r, p o c '\left(t_{k a t}\right)\right)$ and the arrival moment of the train poc $(t)$ $-w r b\left(t w r, p o c\left(t_{k a t}\right)\right)$ should be greater than or equal to that of the vertex $w k$.

\section{The algorithm of train timetable optimization method (KWRP)}

The third point of the paper presents a mathematical model of the train timetable construction. To construct a proper train timetable the multilevel optimization method is used. In this method the tested process is divided into different steps. The transition between stages is associated with taking up an appropriate decision. Regarding these assumptions to the described article problem, the algorithm of construction train timetable method will look as follows:

- STEP 1: definition and parameterization of the railway network,

DECISION: designation of the proposed trains routes of each category in a selected area of the railway network,

- STEP 2: determine the shortest trains routes of each category on a selected area of the railway network,

DECISION: assignment of the traffic flow for transport on each route in an appropriate period of the day and assignment of the type of train set for the task (route) in a specified period of the day and frequencies based on the type of assigned means of transport at the time of the day,

- STEP 3: computation of rail transport offer, 
DECISION: generating of a graphic train timetable and applying ideal train paths on them,

- STEP 4: determine the ideal train paths on the graphic timetable, DECISION: determination of the real train paths on the graphic timetable,

- STEP 5: construct a train timetable.

The first stage and the second refer to the first stage of construction of the train timetable - computation of the transport offer. On the other hand the fourth and fifth stage refer to the physical construction of train timetables. The third stage is common to both phases of construction.

Taking the first and third decision is related to using a search of the shortest path in the graph algorithm - the $A^{*}$ algorithm. The purpose of the $A^{*}$ algorithm is to optimize the sequence of searched nodes. This algorithm calculates the Euclidean distance of a chosen node from the target and adds it to the current designated shortest distance. The nodes of the lowest total distance are visited first. Thus, the $\mathrm{A}^{*}$ algorithm analyses the smaller number of nodes and usually is much faster than other solutions [8]. In the case of the first decision - for a given and parameterized area of the railway network, the $A^{*}$ algorithm will search the shortest paths between a pair of vertices, which in matrix $\mathrm{P}$ (matrix OD) is loaded by traffic flow. In the case of the third decision - the A* algorithm will have the task to find all the shortest paths on the graphic timetable. Edges will be characterized by train journey times through the edge.

The second and fourth decision will be connected with using the Bees Algorithm, which is one of the larger group of swarm algorithms [20]. Like many other solutions concern to the group of swarm algorithms, it imitates the mechanisms that occur in nature, this method is often used with NP class problems. In the case of Bees Algorithm the mimicked mechanism of nature is the way in which the searching of food is carried out by honeybees. In the case of the second decision the role of the Bees Algorithm will be in the distribution of traffic flow on the railway network and optimization of partial criterion functions. In the case of the fourth decision Bees Algorithm will be responsible for maximizing the value of profits associated with the transition of a train on the real route.

\section{Summary and conclusions}

This paper presents an approach to optimize the train timetable on the railway network using multilevel optimization method. This approach is the basis for further work on the problem of train timetable construction. It will be implemented in the form of the optimization procedure using the $\mathrm{A}^{*}$ algorithm, and the Bees Algorithm. Implementation of the procedure will be the subject of the next article.

The application of approach using multilevel optimization method allows for:

1) eliminating manual search of communication line courses, which is applicable in Polish conditions,

2) eliminating operations of manual trains pathing on the graphic timetable.

Moreover, the proposed approach allows the use of the so-called hybrid model consisting of the model (MKOP) computation of transport offer enabling the determination of communication line courses, the type of rolling stock which 
support the system, the frequency on a given line and a model of the physical construction train timetable (MKWR), allowing train pathing on the graphic timetable. It has been shown that this approach allows many factors to be taken into account that influence the final shape of the timetable.

\section{References}

[1] Albrecht, T., Automated timetable design for demand-oriented service on suburban railways. Public Transport, 1(1), pp. 5-20, 2009.

[2] Bałuch, H. \& Starczewska, M., Leksykon terminów kolejowych, KOW media \& marketing, Warszawa, 2011.

[3] Brännlund, U., Lindberg, P.O., Nöu, A. \& Nilsson, J.E., Railway timetabling using Lagrangian relaxation, Transportation Science, 32, pp. 358-369, 1998.

[4] Bussieck, M., Kreuzer, P. \& Zimmermann, U. Optimal lines for railway systems, European Journal of Operational Research, 96, pp. 54-63, 1997.

[5] Caprara, A., Fischetti, M. \& Toth, P., Modeling and solving the train timetabling problem, Operations Research, 50, pp. 851-861, 2002.

[6] Caprara, A., Kroon, L., Monaci, M., Peeters, M. \& Toth, P., Passenger Railway Optimization (Chapter 3), Handbooks in Operations Research and Management Science - Vol. 14: Transportation, ed. Barnhart, C. \& Laporte, G., North-Holland: Elsevier, pp. 129-188, 2007.

[7] Claessens, M., Van Dijk, N. \& Zwaneveld, P., Cost optimal allocation of passenger lines, European Journal of Operational Research, 110, pp. 474489, 1998.

[8] de Smith, M.J., Goodchild, M.F. \& Longley, P.A., Geospatial Analysis: A Comprehensive Guide to Principles, Techniques and Software Tools (2nd ed.). Troubador Publishing, Leicester, 2007.

[9] Dienst, H., Linienplanung in Spurgeführten Personenverkehr mit Hilfe eines Heuristischen Verfahrens (PhD thesis), Technische Universität Braunschweig, 1978.

[10] Ficoń, G., Wyznaczanie wieloetapowej strategii rynkowej za pomocą metod programowania dynamicznego, Zeszyty Naukowe Akademii Marynarki Wojennej, 2 (165), pp. 5-22, 2006.

[11] Gajda, B., Technika ruchu kolejowego. Cz. II - Technologia ruchu kolejowego, Wydawnictwa Komunikacji i Łączności, Warszawa, 1983.

[12] Goossens, J., Van Hoesel, C. \& Kroon, L., A branch-and-cut approach for solving railway line-planning problems, Transportation Science, 38, pp. 379-393, 2004.

[13] Jacyna, M., Żak, J., Jacyna-Gołda, I., Merkisz, J., Merkisz-Guranowska, A. $\&$ Pielecha, J., Selected aspects of the model of proecological transport system. Journal of KONES Powertrain and Transport, 20, pp. 9-20, 2013.

[14] Jovanovic, D. \& Harker, P.T., Tactical scheduling of rail operations: The SCAN I system. Transportation Science, 25, pp. 46-64, 1991.

[15] Nowosielski, L., Organizacja przewozów kolejowych, Kolejowa Oficyna Wydawnicza, Warszawa, 1999. 
[16] Kroon, L.G., Dekker, R. \& Vromans, M.J.C.M., Cyclic railway timetabling: A stochastic optimization approach. Technical Report ERS - Erasmus University Rotterdam, 051, 2005.

[17] Kroon, L., Huissman, D. \& Maroti, G, Optimization models for railway timetabling (Chapter 8). Railway Timetable \& Traffic, ed. Hansen, I.A. \& Pachl, J., Eurailpress, Hamburg, pp. 135-151, 2008.

[18] Oliveira, E. \& Smith, B.M., A job-shop scheduling model for the single-track railway scheduling problem, Research Report Series-University of Leeds School of Computer Studies LU SCS RR, (21), 2000.

[19] Nachtigall, K. \& Voget, S., A genetic algorithm approach to periodic railway synchronization, Computers \& Operations Research, 23, pp. 453-463, 1996.

[20] Pham, D.T., Ghanbarzadeh, A., Koç, E., Otri, S., Rahim, S. \& Zaidi, M., The Bees Algorithm - A Novel Tool for Complex Optimization Problems, I Proceedings of the 2nd Virtual International Conference on Intelligent Production Machines and Systems (IPROMS 2006), pp. 454-459, 2006.

[21] Pielas, Cz., Organizacja ruchu kolejowego, Wydawnictwa Komunikacji i Łączności, Warszawa, 1968.

[22] PKP Polskie Linie Kolejowe S.A.: Regulamin przydzielania tras pociagów $i$ korzystania $z$ przydzielonych tras pociagów przez licencjonowanych przewoźników kolejowych $w$ ramach rozkładu jazdy 2013/2014, www.plksa.pl/

[23] Serafini, P. \& Ukovich, W., A mathematical model for periodic event scheduling problems, SIAM Journal on Discrete Mathematics, vol. 2, pp. 550-581, 1989.

[24] Scholl, S., Customer-oriented line planning (PhD thesis), University of Kaiserslautern, 2005.

[25] Szpigel, B., Optimal train scheduling on a single track railway, Operation Research'72, ed. Ross, M., North-Holland, Amsterdam, pp. 343-351, 1973. 